\title{
INVESTIGATION OF THE CHARACTERISTICS OF ELASTICISED WOVEN FABRIC BY USING PBT FILAMENT YARNS
}

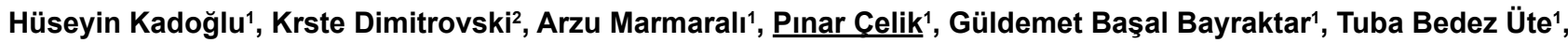 \\ Gözde Ertekin', Andrej Demšar², Klara Kostanjek²
}

${ }^{1}$ Ege University, Faculty of Engineering, Department of Textile Engineering, Bornova, 35100, İzmir, Turkey

${ }^{2}$ University of Ljubljana, Faculty for Natural Sciences and Engineering, Department of Textiles, Ljubljana, Slovenia

\begin{abstract}
:
Owing to growing demand for comfortable clothes, elastane filament yarns are being used in fabrics for several garments. In this study, core spun yarns were produced with cotton fibres and PBT/ elastane filament yarns (cotton as sheath material, PBT yarn and elastane as core yarns). Twill woven (1/3 Z) fabrics were produced by using core spun yarns (30 tex) and cotton yarns (30 tex) as weft, and 100\% cotton yarn (59 tex) as warp yarns. The fabrics consisting of PBT were washed at $100^{\circ} \mathrm{C}$ for 30 minutes to gain the elasticity. The woven fabrics' weight, thickness, elongation, permanent elongation, dimensional stability, air permeability, thermal conductivity, thermal absorptivity characteristics were tested and statistically evaluated. According to the results, the fabrics containing PBT and elastane filaments had similar elongation and shrinkage values. PBT filament yarns have a great potential to produce lightweight elastic fabrics.
\end{abstract}

\section{Keywords:}

Core-spun yarns, elastane, PBT yarns, thermal comfort properties, woven fabrics

\section{Introduction}

Over the last few years, the expectations from the fabrics have changed with the development of textile technology and improved living standards. For clothing and technical purposes of modern everyday life, there is a higher demand for woven fabrics with higher elastic properties under small loads. To get higher elasticity of woven fabrics the most common method is the incorporation of elastane or similar high elastic yarns into woven structure. Use of elastane and similar elastic yarns usually makes products more expensive due to usage of this additional elastic component in the fabric. In addition, the speed of the production process is lowered due to higher elasticity of the material; therefore it is not possible to use the maximum production speed of the available equipment. Finally, woven fabrics with higher elasticity require more delicate cleaning procedures (washing and ironing under lower temperature) in order to retain their elastic properties.

PBT (polybutylene terephthalate) is a textured polyester filament yarn with properties of stretch and elasticity. PBT had a lower Tdi (initial degradation temperature) value, lower tensile strength and similar surface characteristics compared to regular PET (polyethylene terephthalate) [1]. The elasticity of PTT (polytrimethylene terephthalate), PBT, PA66 filaments and core-spun yarns with elastane was compared. Test results indicated that PTT filaments exhibit the lowest modulus and highest elongation recovery ratio, the modulus and recovery ratio of PBT is between PTT and PA66 (polyamide 6-6), elastane has the longest elongation but the core-spun yarn with elastane shows the lowest recovery ratio because of the skin fibre [2].

PBT yarn has higher stretch and recovery compared to standard polyester types and this property is also improved by special texturing conditions. The exceptional stretch and recovery of PBT yarn are achieved through high elastic shrinkage in finishing processes. The outstanding characteristics of PBT are chlorine, salt water and colour fading resistance. PBT does not absorb water, which makes the fabrics with PBT light weight under water. Besides, PBT provides a good form fitting property to the fabric. These characteristics make PBT yarns a good candidate for swimsuits [3].

The chemical resistance of PBT yarns is better than elastane. PBT has good dyeing properties. It can be dyed in bright colours with disperse dyes under the atmospheric pressure without the need for a carrier. The durability, dimensional stability, and elasticity of PBT are preferable and not affected by temperature.

PBT yarns can be widely used in knitted and woven fabrics as an alternative to elastane yarns. The stretch characteristic of the PBT containing fabrics depends on the amount of PBT used and the fabric construction. Briefly, the PBT stretch yarn has a great potential in the field of sanitary materials, clothing (sportswear, swimwear, casual wear fabrics) and other competitive new products in the future market of elastic fibres [4]. 
According to the literature survey, researches with respect to PBT are mainly focused on nonwoven production, particularly for filtration purposes [5-15]. Besides, an artificial neural network model was developed to predict the seam strength and elongation at break values and cotton, core-spun, and PBT sewing yarns have been used for experimental. [16] Yıldırım et al., prepared a review article on the properties, production processes, dyeing and end-use applications of PBT [17].

There are few studies on the yarns containing PBT filaments. It is found that adding different types of PBT in woven structures improve the elastic properties of fabrics in the inserted direction. PBT filament can be used in the warp direction, without causing significant problems in weaving and weaving preparation processes because yarns containing PBT develop their latent elasticity after thermal treatment. This makes them suitable for lengthwise stretch fabrics [18].

The use of PBT for improving the elastic properties of woven fabrics for any purposes could be of significant advantage concerning the price and production time compared to elastane [19].

The comfort properties of woven polyester/cotton fabrics produced with PET/Co (65/35) and Co (100\%) warp yarns and PET/Co (65/35), PET/Co/DOW XLA ${ }^{\text {TM }}$ (62/31/7) and PBT $(100 \%)$ weft yarns were investigated. Having an elastic fibre in the core of the core-spun yarn that had moderated elastic response after yarn and fabric finishing processes compared against nonelasticized and PBT-elasticized fabrics [20].

UV properties of cotton woven fabrics containing elastane and PBT were compared, according to the results, the weight per square meter and thickness of fabrics containing elastane increased more than those of the fabrics containing PBT filament yarn after thermal treatment. Thus, the fabrics containing elastane had higher ultraviolet protection factor (UPF) than the fabrics containing PBT [21].

The main objective of this research is to investigate the possibilities for using PBT yarn in the production of elastic woven fabrics. The woven fabrics were produced with cottonPBT core spun yarns and PBT filament textured yarn as weft with different constructions. The percentage of shrinkage, the dimensional change of fabrics in warp and weft directions, the permanent elongation of fabrics in warp and weft directions, the fabric thickness, the weight per square meter, the air permeability and thermal comfort properties of the fabrics were tested and evaluated.

\section{Material - Method}

\subsection{Yarn production}

In this study, four different yarns (cotton as sheath material, PBT yarn and elastane as core yarns) were used in the core spun yarn production. Additionally, elastane yarns were fed in three different tensions (Figure 1). The spinning process was performed on Pinter, Merlin lab ring frame. 30 tex core spun yarns were produced with same twist coefficient ( $a$ tex $=4021,5$ ). The codes used for the samples were given in Table 1.

\section{$\underline{2.2 \text { Yarn tests }}$}

The characteristics of the yarns except PBT Filament were measured by using Uster Tester 5 and were given in Table 2 .

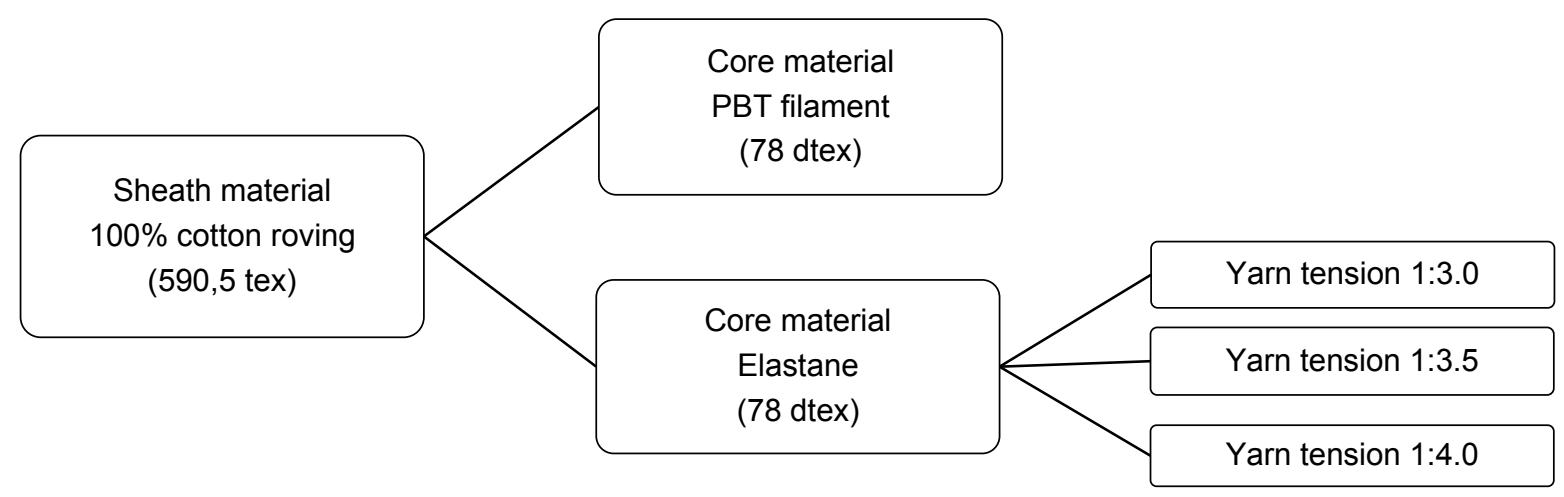

Figure 1. Yarn composition of the core spun yarns

Table 1. The codes used for the yarn samples

\begin{tabular}{|c|c|}
\hline Code & Description \\
\hline PBT/Cotton & PBT core yarn \\
\hline Elastane 3.0 & Elastane (with tension 3.0) core yarn \\
\hline Elastane 3.5 & Elastane (with tension 3.5) core yarn \\
\hline Elastane 4.0 & Elastane (with tension 4.0) core yarn \\
\hline PBT Filament & $1: 1100 \%$ cotton and naked PBT filament \\
\hline $100 \%$ Cotton & 100\% cotton yarn
\end{tabular}


Table 2. Properties of yarn samples

\begin{tabular}{|c|c|c|c|c|c|c|}
\hline & \multicolumn{4}{|c|}{ Yarn evenness } & \multicolumn{2}{|c|}{ Yarn hairiness } \\
\hline & $\begin{array}{l}\text { CV } \\
\%\end{array}$ & $\begin{array}{l}\text { Thin places } \\
(-50 \%) \text { per } \mathbf{k m}\end{array}$ & $\begin{array}{c}\text { Thick places } \\
(+50 \%) \text { per } \\
\text { km }\end{array}$ & $\begin{array}{c}\text { Neps count } \\
(+200 \%) \text { per } \\
\text { km }\end{array}$ & $\begin{array}{l}\text { Hairness } \\
\text { index }\end{array}$ & $\begin{array}{l}\text { sH (standard } \\
\text { deviation } \\
\text { of hairiness) }\end{array}$ \\
\hline $100 \%$ Cotton & 9.33 & 0 & 3.5 & 8.5 & 6.20 & 1.21 \\
\hline PBT/Cotton & 9.20 & 0 & 2.5 & 6.0 & 6.07 & 1.25 \\
\hline Elastane 3.0 & 9.10 & 0 & 2.0 & 3.5 & 6.30 & 1.21 \\
\hline Elastane 3.5 & 9.36 & 0 & 6.0 & 7.5 & 6.54 & 1.24 \\
\hline Elastane 4.0 & 9.34 & 0.95 & 3.13 & 6.28 & 6.46 & 1.22 \\
\hline
\end{tabular}

\subsection{Fabric production}

The yarns were woven with Sulzer rapier weaving machine; 59 tex $100 \%$ cotton yarn and coded yarns listed in Table 1 were used as warp and weft yarns, respectively. Twill weave (1/3 Z) with a warp a density of 12 ends/ cm and a weft density of 28 picks/ $\mathrm{cm}$ were chosen. The fabrics with PBT yarns had to be washed at $100^{\circ} \mathrm{C}$ for 30 minutes to gain elasticity.

\subsection{Fabric tests}

All parameters (weight, dimensional stability, elongation, permanent elongation, thickness and thermal comfort properties) were measured after all fabric samples were washed at $40^{\circ} \mathrm{C}$ according to the TS EN ISO 6330 standard.

Weight values of the fabric samples were measured according to the TS EN 12127 standard. The results of the measurements are averages from the values of 10 readings.

Dimensional stability of the fabric samples after washing was tested in both directions based on the TS EN ISO 6330 standard. The dimensional stability value was calculated according to Equation:

$$
\text { Dimensional stability }(\%)=\frac{\left(l_{B W}-l_{A W}\right)}{l_{B W}} \times 100
$$

where $I_{B W}$ is the dimensions of the specimen before washing $\mathrm{I}_{\mathrm{AW}}$ is the dimensions of the specimen after washing

Elongation and permanent elongation properties were determined by using a stretch testing instrument based on the TS 6071 standard. A stretch testing instrument, consisting of a frame with separate clamps fixed at the top and at the bottom, was implemented to determine the stretch properties of the fabric samples. Sample strips from both weft and warp directions were hung on the apparatus after marking a $250 \mathrm{~mm}$ index in the central part of each specimen. A load, which was hung according to the fabric weight in the bottom hanger, was applied to the fabric sample three times and after the fourth application; the marked distance was measured. The steps of measurement were illustrated in Figure 2.
1. Measurement of the distance with the load after 30 minutes $(B)$

2. Measurement of the distance without load 5 minutes later

3. Measurement of the distance without load $1 \mathrm{~h}$ later

4. Measurement of the distance without load 2 h later $(C)$

Figure 2. Steps of elongation measurement

Elongation and permanent elongation values were calculated as follows:

$$
\text { Elongation }(\%)=\frac{(B-A)}{A} \times 100
$$

where $A$ is the distance marked between the upper and bottom parts of the fabric sample $(250 \mathrm{~mm}), B$ is the distance between the marked points after hanging the fabric sample for 30 minutes with the load $(\mathrm{mm})$

$$
\text { Permanent elongation }(\%)=\frac{(C-A)}{A} \times 100
$$

where $A$ is the distance marked between the upper and bottom parts of the fabric sample $(250 \mathrm{~mm}), \mathrm{C}$ is the distance between the marked points after 2 hours of relaxation $(\mathrm{mm})$

Air permeability values were obtained by using Textest FX 3300 instrument according to TS 391 EN ISO 9237. Its principle depends in the measurement of air flow passing through the fabric at certain pressure gradient $\Delta p$. The results of the measurements are averages from the values of 10 readings.

Alambeta Instrument was used for the determination of the thermal conductivity, thermal absorptivity and thickness values of the fabric samples. The Alambeta basically simulates the 
dry human skin and its principle depends on the mathematical processing of time course of heat flow passing through the tested fabric due to different temperatures of bottom measuring plate $\left(22^{\circ} \mathrm{C}\right)$ and measuring head $\left(32^{\circ} \mathrm{C}\right)[22]$. Whole measurements were repeated five times.

Relative water vapour permeability was measured on Permetest instrument working on similar skin model principle as given by the ISO 11092. The results of the measurements are averages from the values of three readings. All measurements were performed under the standard atmospheric conditions (temperature $20 \pm 2{ }^{\circ} \mathrm{C}, 65 \pm 2 \%$ relative humidity).
As statistical evaluation ANOVA and Student-Newman-Keuls multiple comparison tests were used in $95 \%$ confidence interval.

\section{Results and Discussion}

The elongation, dimensional stability and thermal comfort properties of the fabric samples and their S-N-K Multiple Range Test results are given in Table 3, 4, 5, 6, respectively.

Table 3. The elongation and dimensional stability values of the fabric samples

\begin{tabular}{|c|c|c|c|c|}
\hline Fabric Codes & $\begin{array}{l}\text { Direction of } \\
\text { measurement }\end{array}$ & $\begin{array}{c}\text { Elongation } \\
(\%)\end{array}$ & $\begin{array}{c}\text { Permanent } \\
\text { elongation (\%) }\end{array}$ & $\begin{array}{c}\text { Dimensional } \\
\text { stability } \\
(\%)\end{array}$ \\
\hline \multirow{2}{*}{$100 \%$ Cotton } & Weftwise & 6.13 & 0.4 & -16.38 \\
\hline & Warpwise & 1.8 & 0.2 & -5.81 \\
\hline \multirow{2}{*}{ Elastane 3.0} & Weftwise & 36 & -3 & -34.86 \\
\hline & Warpwise & 1.4 & -0.6 & -6.86 \\
\hline \multirow{2}{*}{ Elastane 3.5} & Weftwise & 35.6 & -1.6 & -34.86 \\
\hline & Warpwise & 0.2 & -0.4 & -6.76 \\
\hline \multirow{2}{*}{ Elastane 4.0} & Weftwise & 33.4 & -1.8 & -35.81 \\
\hline & Warpwise & 0.8 & -0.8 & -7.43 \\
\hline \multirow{2}{*}{ PBT/cotton (before washing) } & Weftwise & 11.6 & 1.2 & - \\
\hline & Warpwise & 1.6 & 0 & - \\
\hline \multirow{2}{*}{ PBT/Cotton } & Weftwise & 45.2 & 11 & -30.95 \\
\hline & Warpwise & 5 & 2 & -8 \\
\hline \multirow{2}{*}{ PBT Filament (Before washing) } & Weftwise & 37 & 0.6 & - \\
\hline & Warpwise & 1.6 & 0 & - \\
\hline \multirow{2}{*}{ PBT Filament } & Weftwise & 94.2 & 9.6 & -35.9 \\
\hline & Warpwise & 3 & 0 & -6.57 \\
\hline
\end{tabular}

Table 4. The thermal comfort, weight and thickness values of the fabric samples

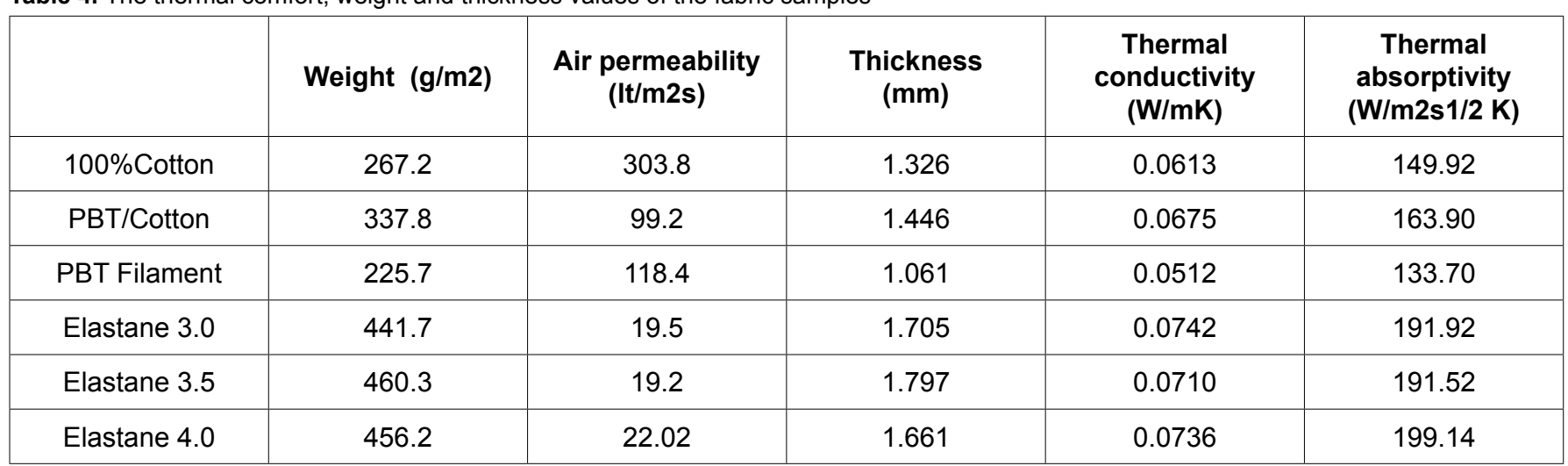


Table 5. Results of the S-N-K Multiple Range Test for the physical properties of the fabric samples

\begin{tabular}{|c|c|c|c|c|c|c|c|c|c|c|c|}
\hline \multicolumn{6}{|c|}{ Elongation (Weftwise) } & \multicolumn{6}{|c|}{ Elongation (Warpwise) } \\
\hline Code & 1 & 2 & 3 & 4 & 5 & Code & 1 & 2 & 3 & 4 & 5 \\
\hline $100 \%$ Cotton & 6.13 & & & & & Elastane 3.5 & 0.2 & & & & \\
\hline Elastane 4.0 & & 33.4 & & & & Elastane 4.0 & 0.8 & 0.8 & & & \\
\hline Elastane 3.5 & & & 35.6 & & & Elastane 3.0 & & 1.4 & 1.4 & & \\
\hline Elastane 3.0 & & & 36.0 & & & $100 \%$ Cotton & & & 1.8 & & \\
\hline PBT/Cotton & & & & 45.2 & & PBT Filament & & & & 3.0 & \\
\hline PBT Filament & & & & & 94.2 & PBT/Cotton & & & & & 5.0 \\
\hline$p$ value & 1.000 & 1.000 & .062 & 1.000 & 1.000 & $p$ value & .073 & .073 & .215 & 1.000 & 1.000 \\
\hline \multicolumn{6}{|c|}{ Permanent Elongation (Weftwise) } & \multicolumn{6}{|c|}{ Permanent Elongation (Warpwise) } \\
\hline Code & \multicolumn{2}{|l|}{1} & \multicolumn{2}{|l|}{2} & 3 & Code & \multicolumn{2}{|l|}{1} & \multicolumn{2}{|l|}{2} & 3 \\
\hline Elastane 3.0 & \multicolumn{2}{|l|}{-3} & & & & Elastane 4.0 & \multicolumn{2}{|c|}{-0.8} & & & \\
\hline Elastane 4.0 & \multicolumn{2}{|l|}{-1.8} & & & & Elastane 3.0 & \multicolumn{2}{|c|}{-0.6} & \multicolumn{2}{|l|}{-0.6} & \\
\hline Elastane 3.5 & \multicolumn{2}{|l|}{-1.6} & & & & Elastane 3.5 & \multicolumn{2}{|c|}{-0.4} & \multicolumn{2}{|l|}{-0.4} & \\
\hline $100 \%$ Cotton & \multicolumn{4}{|c|}{0.4} & & PBT Filament & \multicolumn{2}{|l|}{0} & \multicolumn{2}{|l|}{0} & \\
\hline PBT Filament & & & & & 9.6 & $100 \%$ Cotton & & & \multicolumn{2}{|l|}{0.2} & \\
\hline PBT/Cotton & & & & & 11.0 & PBT/Cotton & & & & & 2.0 \\
\hline$p$ value & \multicolumn{2}{|l|}{.120} & \multicolumn{2}{|l|}{1.000} & .052 & $p$ value & .064 & & .064 & & 1.000 \\
\hline & iensiona & Stabil & (Weftv & se) & & & mensiona & al Stak & ity (Warp & vise) & \\
\hline Code & 1 & & 2 & & 3 & Code & 1 & & 2 & & 3 \\
\hline PBT Filament & -35.90 & & & & & PBT/Cotton & -8.00 & & & & \\
\hline Elastane 4.0 & -35.81 & & & & & Elastane 4.0 & -7.43 & & -7.43 & & \\
\hline Elastane 3.5 & -34.86 & & & & & Elastane 3.0 & & & -6.86 & & -6.86 \\
\hline Elastane 3.0 & -34.86 & & & & & Elastane 3.5 & & & -6.76 & & -6.76 \\
\hline PBT/Cotton & & & -30.95 & & & PBT Filamen & & & -6.57 & & -6.57 \\
\hline $100 \%$ Cotton & & & & & -16.38 & $100 \%$ Cotton & & & & & -5.81 \\
\hline $\mathrm{p}$ value & .159 & & 1.000 & & 1.000 & $p$ value & .169 & & .176 & & .079 \\
\hline
\end{tabular}

\subsection{Elongation - Permanent Elongation - Dimensional Stability}

The elongation values of the PBT Filament and PBT/Cotton fabric samples before and after washing were given in Table 3. According to the statistical analysis, there is a significant difference between the characteristics of PBT fabric samples before and after washing $(p=.000)$. After washing, the elongation value of PBT Filament fabric sample was increased $57.2 \%$ in weftwise and $1.4 \%$ in warpwise, while these values of PBT/Cotton fabric sample in weft- and warpwise were increased $33.6 \%$ and $3.4 \%$, respectively. The results revealed that washing treatment improved the elongation characteristics of the fabric samples containing PBT yarn.

As illustrated in Figure 3 and Table 5, the highest weftwise elongation value was obtained from PBT Filament fabric sample, following by PBT/Cotton fabric sample. Although the weftwise elongation value of PBT/Cotton fabric sample was higher than $100 \%$ Cotton and ones with elastane, the increase in weftwise elongation value of PBT/Cotton fabric sample (increased by $33.6 \%$ ) was smaller than the PBT Filament fabric sample (increased by $57.2 \%$ ). This situation might be explained by the cotton sheath. It is likely that cotton sheath restricted the PBT filament in the core and deteriorates the elongation behaviour of PBT.

When compared the warpwise elongation values of the samples, the elastane fabrics with high tension (3.5 and 4.0) had lower and fabric samples containing PBT had higher elongation values than the others. As it was expected the warpwise elongation values of all samples were very low due to the cotton warp yarn used in all fabric samples. 
Table 6. Results of the S-N-K Multiple Range Test for the thermal comfort properties of the fabric samples

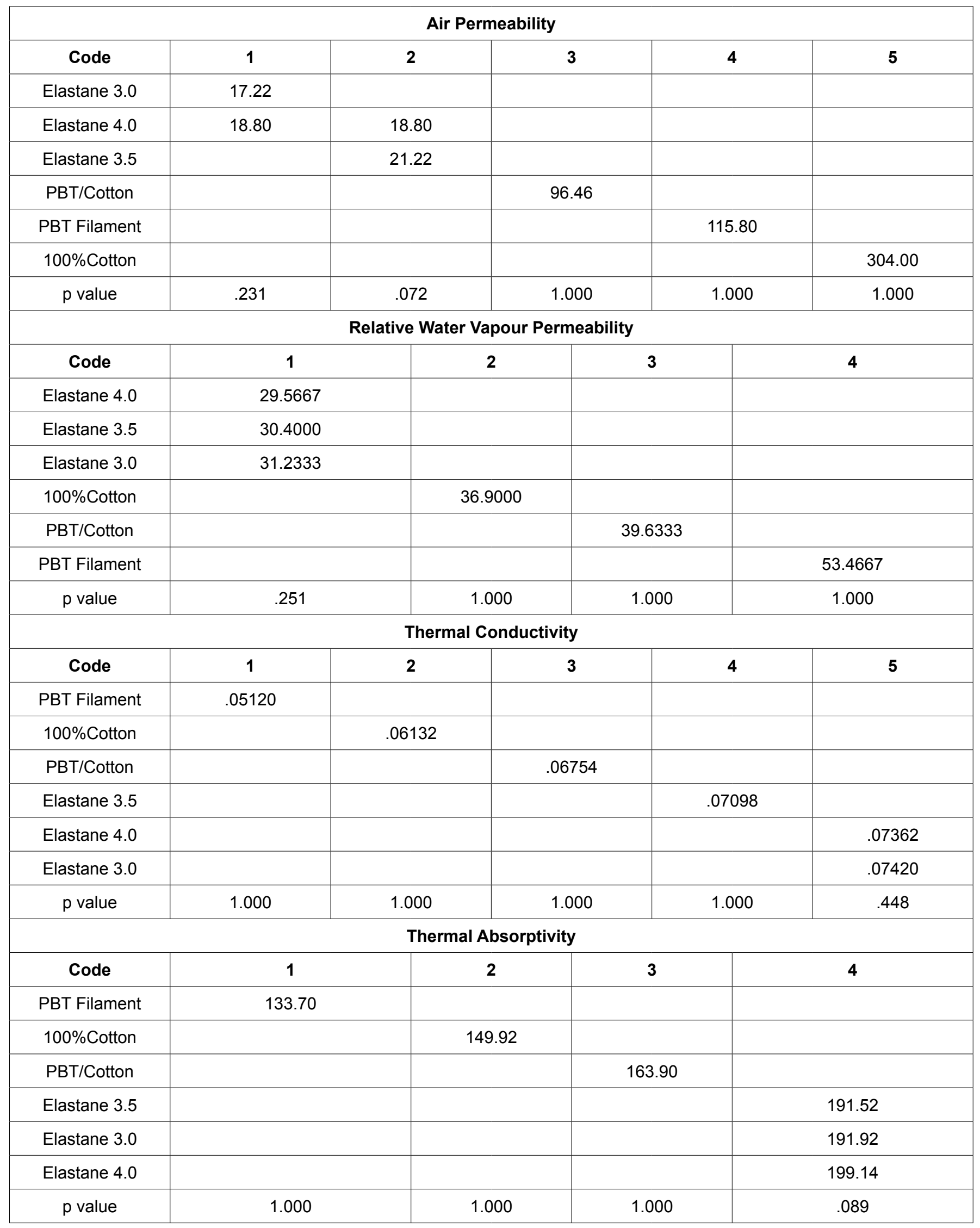


The permanent elongation values of the PBT Filament and PBT/ Cotton fabric samples before and after washing were given in Table 3. Washing had a significant effect on the weftwise permanent elongation value. After washing, the PBT Filament and PBT/Cotton fabric samples' permanent elongation values were increased by $9 \%$ and $9.8 \%$, respectively. In terms of permanent elongation in warpwise, washing didn't have any significant effect for PBT Filament fabric sample, however, for PBT/Cotton fabric, the permanent elongation value after washing was increased by $2 \%$.

The permanent elongation values of the fabric samples are shown in Figure 4. According to the statistical evaluation (Table 5 ), the lowest values were obtained from the fabric samples containing elastane and contrary to elongation; a contraction was occurred with these fabrics. PBT Filament and PBT/Cotton fabric samples had higher permanent elongation characteristics and there wasn't any significant difference between these fabric samples.

The statistical results of warpwise permanent elongation values revealed that, there was not any significant difference between the values of the fabric samples except PBT/Cotton fabric sample.

The results illustrated in Table 3 revealed that, all fabric samples had negative dimensional stability values in both directions. This means that after washing all fabric samples shrunk in both directions, which indicated that pick and end densities in the fabric samples increased.

Figure 5 and Table 5 showed that, shrinkage value of the PBT Filament fabric sample and fabric samples containing elastane yarns were approximately $35 \%$ in weftwise. The lowest shrinkage value was obtained from $100 \%$ Cotton fabric sample following by PBT/Cotton fabric sample.

As compared the dimensional stability of the fabric samples in warpwise, the results indicated that, all fabric samples had higher than $5 \%$ shrinkage value after washing. The highest shrinkage values were obtained from PBT/Cotton and Elastane 4.0 fabric samples.

\subsection{Thermal comfort properties}

As illustrated in Figure 6, the lowest air permeability values belong to the fabric samples woven with elastane yarns. The addition of elastane yarn into the structure led to a decrease in air permeability values. This is thought to be cause of the higher weight and thickness values of these fabric samples. Because the fabrics get heavier and thicker, the amount of air passed through the fabric decreased. $100 \%$ Cotton fabric sample had highest air permeability. It was followed by PBT Filament and PBT/Cotton fabric samples.

Figure 7 and Table 6 showed that PBT Filament fabric sample and fabric samples containing elastane yarns (Elastane 3.0, $3.5,4.0$ ) exhibited the highest and the lowest water vapour permeability values, respectively.

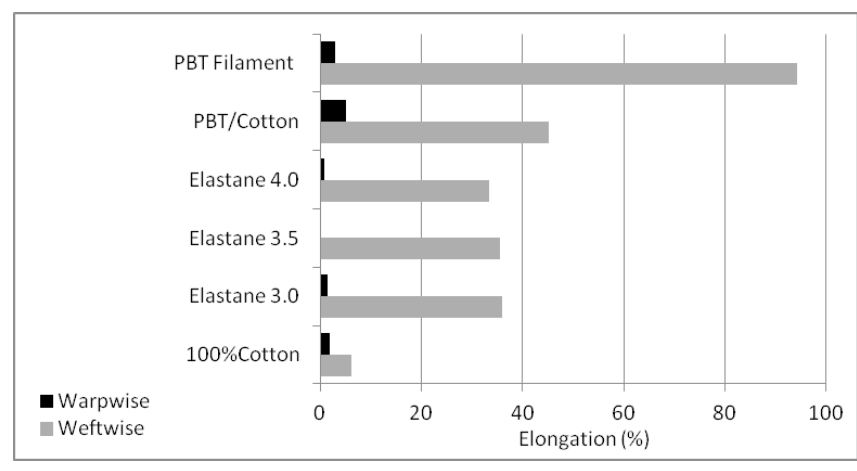

Figure 3. Elongation values (warp- and weftwise) of the fabric samples

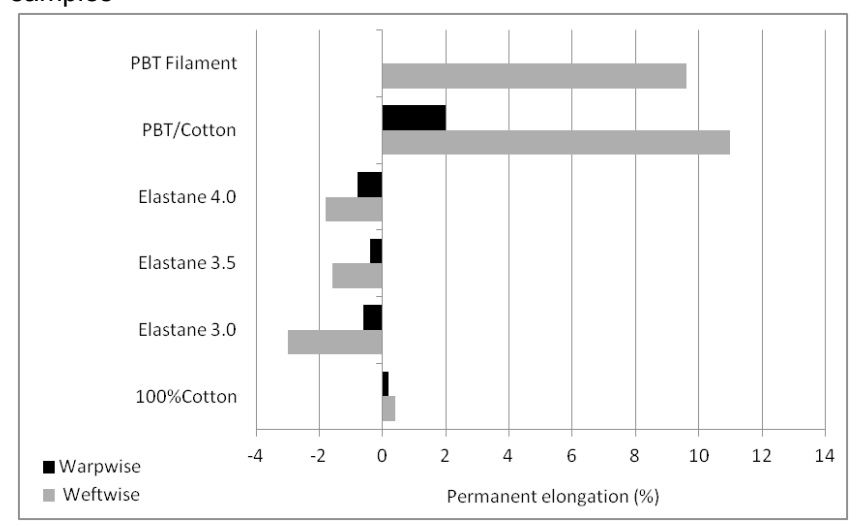

Figure 4. Permanent elongation values (warp- and weftwise) of the fabric samples

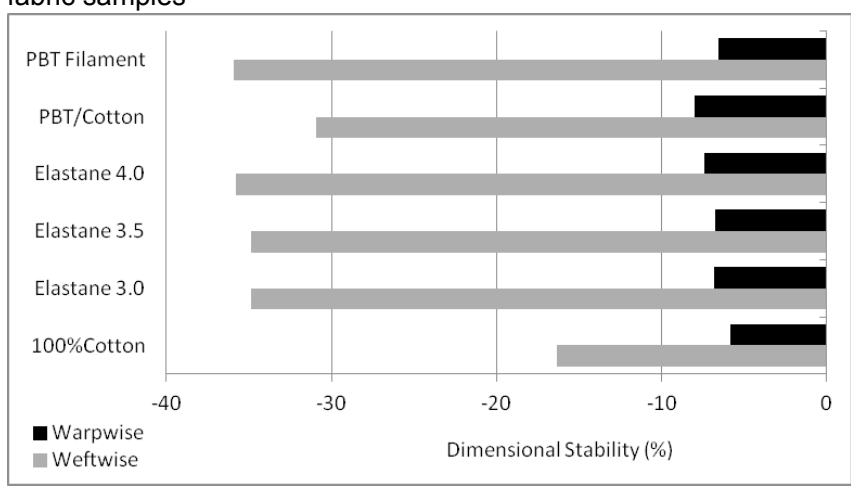

Figure 5. Dimensional stability values (warp- and weftwise) of the fabric samples

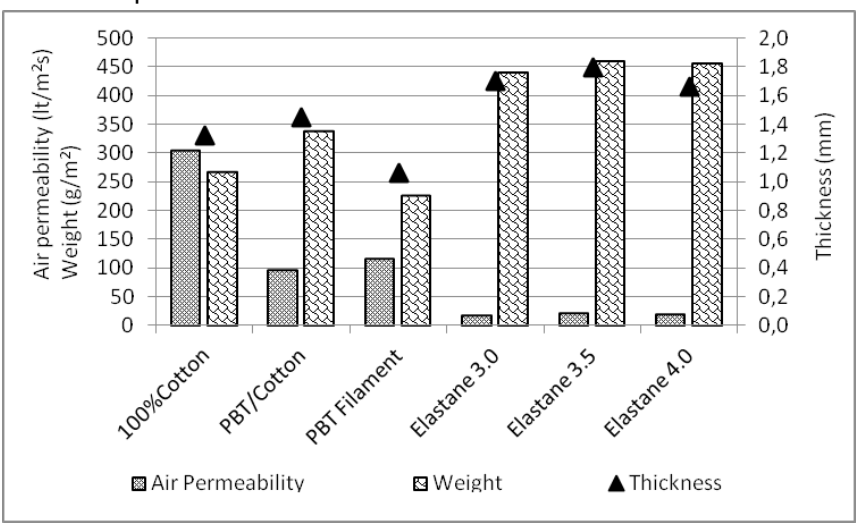

Figure 6. Air permeability values of the fabric samples 


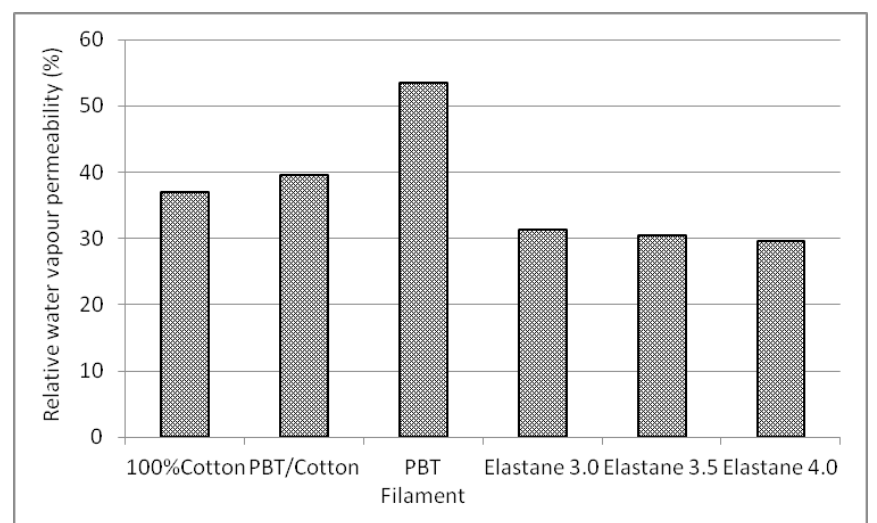

Figure 7. Relative water vapour permeability values of the fabric samples

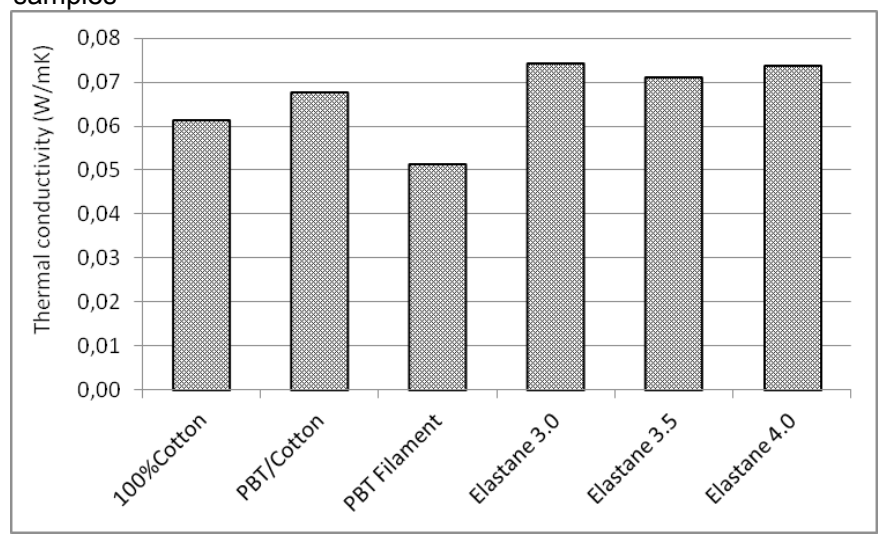

Figure 8. Thermal conductivity values of the fabric samples

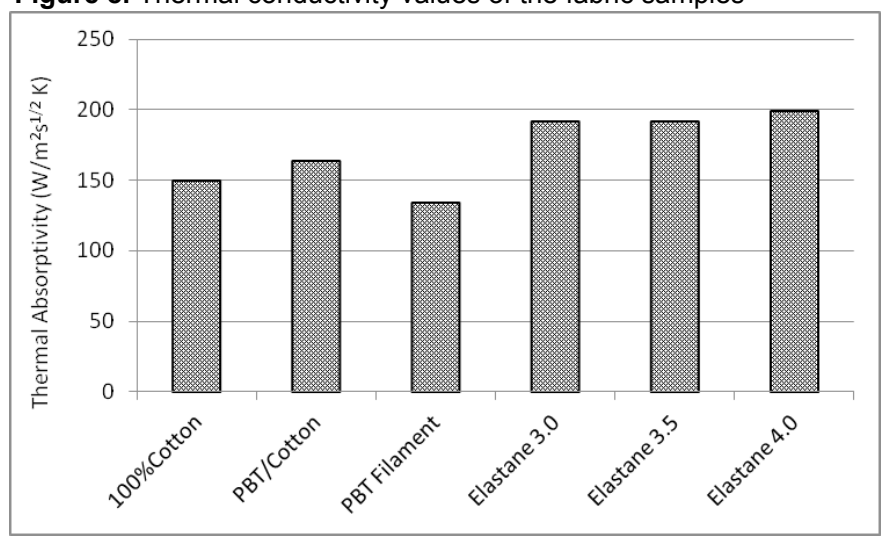

Figure 9. Thermal absorptivity values of the fabric samples

Thermal conductivity and thermal absorptivity values of the samples are given in Figure 8 and 9, respectively. The results indicated that Elastane 3.0 and 4.0 fabric samples provided higher thermal conductivity values following by Elastane 3.5 fabric sample and there was not any significant difference between the thermal properties of Elastane 3.0 and 4.0 fabric samples. On the other hand, the lowest thermal conductivity value was determined in PBT Filament fabric sample.

Additionally fabric samples containing elastane yarns (Elastane 3.0, 3.5, 4.0) with higher thermal absorptivity values gave cooler feeling at initial touch and PBT Filament fabric sample had the lowest thermal absorptivity value. This situation might be explained by the thermal conductivity characteristics of these fabrics. Thermal absorptivity increased with the increasing thermal conductivity and density of fabrics.

\section{Conclusion}

In this study, the fabrics woven with PBT, elastane and cotton yarns were analysed in terms of elongation, dimensional stability and thermal comfort. The weight, thickness, elongation, permanent elongation, dimensional stability, air permeability, thermal conductivity, thermal absorptivity and relative water vapour permeability properties of the fabric samples were tested and evaluated statistically. The results indicated that:

-Washing treatment had a significant effect on the elongation and permanent elongation values of the fabric samples containing PBT. After washing, the elongation value of PBT Filament fabric sample was increased $57.2 \%$ in weftwise and $1.4 \%$ in warpwise, while these values of PBT/Cotton fabric sample in weft- and warpwise were increased $33.6 \%$ and $3.4 \%$, respectively. Additionally the PBT Filament and PBT/ Cotton fabric samples' permanent elongation values were increased by $9 \%$ and $9.8 \%$, respectively.

- PBT Filament and PBT/Cotton fabric samples fabrics had higher elongation values in both directions compared with the other fabric samples.

-The lowest permanent elongation values were obtained from the fabric samples containing elastane yarns and instead of elongation a contraction was occurred with these fabric samples.

-The shrinkage value of the PBT Filament fabric sample and fabric samples containing elastane yarns were approximately $35 \%$ in weftwise. The lowest shrinkage value was obtained from $100 \%$ Cotton fabric sample following by PBT/Cotton fabric sample. All fabric samples had higher than $5 \%$ shrinkage value in warpwise after washing. The highest shrinkage values were obtained from PBT/Cotton and Elastane 4.0 fabric samples.

-In terms of elastic characteristics, PBT Filament and PBT/ Cotton fabric samples had higher elongation values in warpand weftwise. Additionally PBT Filament fabric sample and fabric samples containing elastane yarns had similar shrinkage values in both directions. PBT Filament fabric sample with higher elongation and similar shrinkage characteristics provided more elastic behaviour with lower weight and thickness values.

-The fabric samples containing elastane yarns had lower air permeability compared to others. $100 \%$ Cotton fabric sample exhibited the highest air permeability following by PBT Filament and PBT/Cotton fabric samples.

-PBT Filament fabric sample and fabric samples containing elastane yarns (Elastane 3.0, 3.5, 4.0) had the highest and the lowest water vapour permeability values, respectively.

-The fabric samples containing elastane yarns had higher thermal conductivity and gave the cooler feeling at initial touch due to their higher thermal absorptivity characteristic.

-PBT Filament fabric sample had lower thermal conductivity and absorptivity values. 
According to these results, PBT filament yarns have a great potential to produce lightweight elastic fabrics. Besides, fabrics with PBT filament yarns have better durability to textile finishing processes and longer lifetime than the fabrics containing elastane.

\section{ACKNOWLEDGEMENT}

This research is financially supported by the Scientific \& Technological Research Council of Turkey (TUBITAK) and Slovenian Research Agency (ARRS) within a bilateral project (Project No: 110M420) conducted by Prof. Dr. Hüseyin Kadoğlu, Ege University, Turkey and Prof. Dr. Krste Dimitrovski, University of Ljubljana, Slovenia.

\section{References}

[1] Arık, B., Bozacı, E., Demir, A., Özdoğan, E., 2013, "Thermogravimetric, Microscopic and Mechanical Analyses of PBT and PET Yarns ", Tekstil ve Konfeksiyon 23(2), 2013, pp101-106.

[2] Wang, F.M., Li, H., Li, J.G., Wu, X.Y., Liu, C.M., 2004, "Comparison of elasticity of PTT and other elastic fibers", Quality Textiles for Quality Life, Vol 1-4, pp 441-443.

[3] http://www.macroint/co.com/category/19/PBT.html

[4] http://www.heshili-pbt.com/news/201304094.html]

[5] Liu, H. Zheng, Y., Gurgel, P.V., Carbonell, R.G., 2013, "Affinity membrane development from PBT nonwoven by photo-induced graft polymerization, hydrophilization and ligand attachment", Journal of Membrane Science; Vol.428, pp 562-575.

[6] Cao, Y.; Liu, J., Zhong, R., et al., 2012, "Surface modification of PBT nonwoven fabrics used for blood filtration and their blood compatibility study", Artificial Cells Blood Substitutes And Biotechnology, Vol.40 (5), pp 317-325.

[7] Cao, Y., Wang, H., Zhong, R., Liu, JX, 2012, "Preparation of Heparin-Modified PBT Nonwoven Fabrics and Their Application as Leukocyte Removal Filters, Poster, Vox Sanguinis, Vol.103, Special Issue Supplement:1 p14.

[8] Kovaleva E.V., Lapovskii V.V., Shevlik N.V., and Geller B.E., (2006), "Study of the Reological Properties of Melts of Polypropylene and Polybutylene Terephthalate Blends", Fibre Chemistry, Vol. 38, No:5.

[9] Yuan, L., Wang, L., Xu, Q.-Y., Lim, P.J., Guo, Z.H., et al., 2012, "Rheological Study on of PBT with High Melt Flow Index", Advanced Materials Research Vol.487, pp 644648.

[10] Cao, Y., Wang, H., Yang, C., Zhong, R., Lei, Y., Sun, K., Liu, J., 2011, "In vitro studies of PBT Nonwoven Fabrics adsorbent for the removal of low density lipoprotein from hyperlipemia plasma", Applied Surface Science Vol.257 (17), $p p$ 7521-7528.
[11] Chen, Y., Tang, X., Chen, B.; Qiu, G., 2011, “Atmospheric Pressure Plasma Vapor Treatment of Thermo-sensitive Poly (N-isopropylacrylamide) and its Application to Textile Materials", Journal of Fiber Bioengineering \& Informatics 4:3, pp 285-290.

[12] Yang, C., Sun, K., Liu, J., Wang, H., Cao, Y., 2010, "Zwitterionic sulfobetaine-modified non-woven fabric for blood filtration", Polymer International, Vol.59 (9), pp 12961302.

[13] Zuo, F., Tan, D. H., Wang, Z., Jeung, S., et al., 2013, "Nanofibers from Melt Blown Fiber-in-Fiber Polymer Blends" ACS Macro Letters Vol.2 (4), pp 301-305.

[14] Kim E. J., Yeo G.-D., Pai C.M., Kang I.-K., (2009), "Preparation of Surface-Modified Poly(butylene [terephthalate) Nonwovens and Their Application as Leukocyte Removal Filters", J Biomed Mater Res Part B: Appl Biomater90B: 849-856, DOI: 10.1002/jbm.b.31354.

[15] Gerard, E., Bessy, E., Henard, G., et al., 2011, "Surface Modification of Poly(butylene terephthalate) Nonwoven by Photochemistry and Biofunctionalization with Peptides for Blood Filtration", Journal of Polymer Science Part A-Polymer Chemistry", Vol.49(23), pp 5087-5099.

[16] Yildiz, Z., Dal, V., Ünal, M., Yildiz, K., 2013, "Use of Artificial Neural Networks for Modelling of Seam Strength and Elongation at Break", Fibres \& Textiles in Eastern Europe, 21, 5(101): 117-123.]

[17] Dimitrovski K., Kostajnsek K., Gündüz A., Tanyeli M., Akleylek A.,2012, Properties of Cotton-Like Woven Fabrics Containing Different Types of PBT Yarns in the Weft", 6th International Textile Clothing \& Design Conference-Magic World of Textiles, October 7-10, Dubrovnik, Croatia.

[18] Yıldırım, F.F., Yavaş, A., Avinç, O.O., 2012, "Overview of Poly (Buthylene Terephtalate) Fibres", Journal of Textiles and Engineer, Vol. 19 (87), pp 29-42, DOI: 10.7216/130075992012198705.

[19] Dijana S., Dimitrovski, K., 2012, "Study of cotton woven fabrics with added polybutylene terephthalate yarns", Tekstil: Journal of Textile \& Clothing Technology;JanJun2012, Vol. 61 Issue 1-6, p18.

[20] Verdu, P., M. Rego, J.M., J. Nieto, J., et al.,2009, "Comfort Analysis of Woven Cotton/Polyester Fabrics Modified with a New Elastic Fiber, Part 1 Preliminary Analysis of Comfort and Mechanical Properties", Textile Research Journal Vol 79(1): 14-23 DOI: 10.1177/0040517508090888

[21] Celik, P., Bedez Ute, T., Kadoglu, H., Marmarali, A., Ertekin, G., Kostanjnsek, K., Demsar, A., Dimitrovski, K., 2014, Comparative study of UV properties of cotton woven fabrics containing Lycra and PBT, 7th International Textile, Clothing\&Design Conference - Magic World of Textiles, October 05th to 8th, Dubrovnik, Croatia.

[22] Hes, L., Thermal Comfort Properties of Textile Fabrics in Wet State, In "Proceedings of XI. International Izmir Textile and Apparel Symposium", Turkey, (2007). 